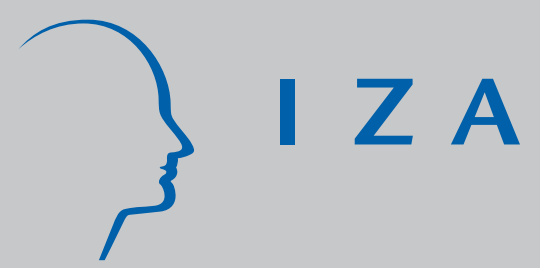

IZA DP No. 421

Divide et Impera: Negotiating with a Stakeholder

Paola Manzini

February 2002 


\title{
Divide et Impera: \\ Negotiating with a Stakeholder
}

\author{
Paola Manzini \\ Queen Mary, University of London and IZA, Bonn
}

Discussion Paper No. 421
February 2002

IZA

P.O. Box 7240

D-53072 Bonn

Germany

Tel.: +49-228-3894-0

Fax: +49-228-3894-210

Email: iza@iza.org

This Discussion Paper is issued within the framework of IZA's research area Evaluation of Labor Market Policies and Projects. Any opinions expressed here are those of the author(s) and not those of the institute. Research disseminated by IZA may include views on policy, but the institute itself takes no institutional policy positions.

The Institute for the Study of Labor (IZA) in Bonn is a local and virtual international research center and a place of communication between science, politics and business. IZA is an independent, nonprofit limited liability company (Gesellschaft mit beschränkter Haftung) supported by the Deutsche Post AG. The center is associated with the University of Bonn and offers a stimulating research environment through its research networks, research support, and visitors and doctoral programs. IZA engages in (i) original and internationally competitive research in all fields of labor economics, (ii) development of policy concepts, and (iii) dissemination of research results and concepts to the interested public. The current research program deals with (1) mobility and flexibility of labor, (2) internationalization of labor markets, (3) the welfare state and labor markets, (4) labor markets in transition countries, (5) the future of labor, (6) evaluation of labor market policies and projects and (7) general labor economics.

IZA Discussion Papers often represent preliminary work and are circulated to encourage discussion. Citation of such a paper should account for its provisional character. A revised version may be available on the IZA website (www.iza.org) or directly from the author. 
IZA Discussion Paper No. 421

February 2002

\title{
ABSTRACT \\ Divide et Impera: Negotiating with a Stakeholder
}

In many kinds of bilateral negotiations the resolution of the issues at stake has an impact which extends beyond the remits of the parties directly involved (e.g. labour negotiations in sectors of public interest, where a strike would impact on the public at large). Once this is recognised, negotiations ought to account for the interests of such stakeholder, whose stake is linked to the original negotiations. This interplay of different interests may introduce a strategic incentive to delay agreement in order to win the maximum concessions from one's opponents.

JEL Classification: $\quad \mathrm{C} 7, \mathrm{D} 74, \mathrm{~J} 5$

Keywords: Stakeholders, bargaining, war of attrition

\author{
Paola Manzini \\ Department of Economics \\ Queen Mary, University of London \\ Mile End Road \\ London E1 4NS \\ U.K. \\ Tel.: +44 2078825083 \\ Fax: +44208983 3580 \\ Email: p.manzini@qmul.ac.uk
}

\footnotetext{
* Financial support from ESRC grant R000223438 is gratefully acknowledged. I wish to thank Giulio Fella and Marco Mariotti for helpful comments and Clara Ponsatí for useful discussions on related matters. Any errors are my own.
} 


\section{Introduction}

There are countless negotiations where agreement is reached only after protracted dealings. Arguably, in many cases the main cause of delay is apparent, be it the complexity of the issues debated or uncertainty over the real needs of the negotiating parties. Yet, there are situations where issues are straightforward and negotiating stances well publicised (e.g. the renegotiation of a national employment contract, where all data and accounts are publicly available), and still agents cannot manage to avoid prolonged delays before reaching an agrement. Why?

In this paper I argue that the interplay of parallel sets of negotiations is one important source of inefficiencies when there are no other obvious ones (i.e. under complete information). Indeed, there are several occurrences where, even once they are stripped down to their essential features, bilateral discussions over an issue of contention do have effects over third parties. This is typically the case for matters of public concern, such as transport, health, the supply of utilities. Whenever industrial action looms on negotiations in any of these domains, governments have a vested interest in a speedy resolution of the dispute to minimise the adverse consequences on the public at large. Thus the remits of the original negotiations over wages, layoffs, working conditions and so on extend well beyond the concerns of the parties directly involved - the third party which is unwillingly pulled into negotiations has a concrete interest to put up resources and protect his own stake in the dispute.

Once this feature is recognised, the original set of negotiations in effect run in parallel with another set of negotiations involving the stakeholder. The crucial issue is that the resources bargained upon on the two negotiating tables are interconnected, in the sense that now the terms of each agreement can be conditioned on the outcome of the other one. The resolution of each stalemate hinges upon the resolution of the 'meta'-dispute, which encompasses all parties: this creates the potential for a strategic interplay between the two sets of negotiations (the original one and the one with the stakeholder), which may 
be the cause of severe inefficiency. The reason for this is simple, and easier to illustrate with an example. Consider the case of a firm threatening to close a plant during an economic downturn. The impact that job losses may have on the economy at large and on voter behaviour may be enough to warrant the involvement of the government, that could intervene with a handout to the firm. So in effect two deals need to be stricken, one between the firm and its workforce (e.g. on reduced pay versus layoffs), and one between the firm and the government (over financial support). The crucial aspect is that in considering a concession over the terms of employment to the workforce, the firm will bear in mind the development of its negotiations with the stakeholder. Similarly, no financial support will be forthcoming from the government unless agreement is reached on employment issues. In this setting the firm is pivotal, in that its agreement is needed in both sets of negotiations for a successful resolution of the dispute. Neither the workforce nor the government can on their own guarantee a quick resolution, as neither of them can influence directly the set of negotiations in which they are not a bargaining party. To the contrary, the firm can single-handedly draw the dispute to a speedy conclusion, by conceding on both negotiating tables; or impose a drawn out process to both of the other sides. Provided the gains from obtaining its most favoured alternative are sufficiently high, the latter may be an attractive prospect for the firm.

One could contend that this sort of inefficiency could be removed if all parties were involved in negotiations over all issues, so as to have a trilateral negotiating table at the outset. Besides the fact that this may be sometimes either unfeasible or undesirable for some of the parties, multilateral negotiations generally do not solve inefficiencies ${ }^{1}$.

Alternatively, one could argue that inefficiencies may be removed if governments strengthen their reliance on legislation; in the example above, the introduction of tighter

\footnotetext{
${ }^{1}$ It is well known that strategic models of multilateral bargaining generate delayed agreement, unless restrictions are imposed on the strategies or the bargaining protocols (see e.g. [10], [9] and references therein). This is even more so when a stakeholder that can give out resources is present; see e.g. [8] and [12].
} 
rules on consultation of the workforce, the imposition of higher levels of redundancy pay, and could arguably eliminate the need for the government to take an active role in specific negotiations, thus removing the source of inefficiency outlined above. In fact, though, the tendency of modern governments it is towards less and less mandatory intervention, with the consequence that governments become progressively more active players in negotiations, rather than 'referees'2. For instance, in industrial relations the rules for consultation with the trade unions in effect do not prevent massive layoffs when companies feel this is needed. A case in point is the one involving the Anglo-Dutch steel group Corus, that in February 2001 announced its intention to cut 6050 jobs in the UK. After months of negotiations, trade unions eventually failed to persuade Corus to fund retraining of employees for employment in other sectors, and in May Corus confirmed it was to go ahead with the announced layoffs. In the event the government tried and failed to induce a rethink of the massive job cuts, and finally intervened with substantial financial support, in a package comprising lump sum payments to laid off workers and their retraining ${ }^{3}$.

In the rest of the paper I study the effect that the parallel development of two sets of interconnected negotiations has on the final settlement.

My modelling strategy starts from the observation that negotiations typically do not take place in a vacuum: they may come at the end of a previous contract, in which case there may be some natural default option (e.g. the previous agreement), and the negotiating parties may avail themselves of external independent advice ${ }^{4}$. In short, there

\footnotetext{
${ }^{2}$ For example, in the UK the Secretary of State for the Department of Trade and Industry Byers declared "Government needs to be active but must not be interventionist. In doing so I reject the approaches of the past. That of the new right who took the line that the market should be the 'be all and end all' and that government should simply keep out. And that of the old left who believed in large scale intervention, coupled with massive state subsidies which either sought to back winners or to rescue failing companies." See [5].

${ }^{3}$ Incidentally, note that in this instance Corus was in effect involved in two parallel sets of negotiations, one with the unions over the conditions of layoffs, and one with the Government to win financial support for re-training.

${ }^{4}$ For instance in the UK Pay Review Bodies make recommendations to the government about the
} 
will be preferred settlements for each side which, if incompatible, trigger negotiations. Thus initially (in section 2) I model negotiations as a war of attrition between the two contending parties, each putting forward its most preferred settlement. In the standard war of attrition setup probabilistic delays can be obtained in equilibrium under complete information $^{5}$ by relying on mixed strategies, which are however often troublesome to justify as a deliberate choice $^{6}$. In this respect, the interesting aspect of my simple model is that delayed equilibria occur in pure strategies, as discussed in section 3.

In section $4 \mathrm{I}$ endogenise the process by which the demands are formulated, and show that this does not eliminate inefficient (i.e. delayed) equilibria. Finally section 5 concludes.

\section{The model}

The firm is engaged in two sets of negotiations, one with its employee over wages, and one with the government over financial support. All agents discount utility at the istantaneous rate $r_{i}$ (with $i=f, w, g$ for firm, worker and government respectively), so that an agreement reached at time $t$ over a payment $x$ to agent $i$ yields to this agent a utility of $x e^{-r_{i} t}$ in present discounted value. To capture the feature that the two bargaining problems belong to the larger 'meta' dispute, agents obtain their payoff only when both sets of negotiations are over ${ }^{7}$.

'appropriate' level of pay for various public sector employees. In Canada conciliators and mediators can be appointed by the government to help resolve management-union disputes. See [3] .

${ }^{5}$ See [4], who characterise the Nash equilibria of the war of attrition under complete iformation for a general class of payoff functions.

${ }^{6}$ See for instance the excellent discussions in [11].

${ }^{7}$ This model is distinct from the standard war of attrition in that there are two sets of interrelated negotiations running alongside. This also sets my setup apart from generalised war of attrition models (see [2] or more recently [7]), where $m \geq 2$ agents compete for $n<m$ prizes. In that case multiple agents compete in the same war of attrition, and the game terminates once $n-m$ agents have conceded. To the contrary, this paper is concerned with multiple wars of attrition. 
In negotiations between the firm and the worker, let $w_{w}$ be the worker's preferred settlement, and $w_{f}<w_{w}$ the wage preferred by the firm. Normalising firm's revenues to unity, the corresponding profits for the firm are $\pi_{w}=1-w_{w}$ if the worker's proposal goes through, and $\pi_{f}=1-w_{f}$ if the firm's proposal goes through. If agent $i=w, f$ concedes at time $t_{i}$, then this implies agreement on wage $w_{j \neq i}$. If both agents concede at the same time, then each of the two agreements is implemented with equal probability. The time when an agreement is enjoyed depends on whether or not the parallel set of negotiations (between the firm and the government) is over or not. If it is, then the wage agreement is implemented immediately upon agreement. If not, then the wage settlement is implemented as soon as agreement is reached in the firm-government negotiations. Let $\tau=\min \left\{\tau_{g}, \tau_{f}\right\}$ denote the time at which an agreement is reached in firm-government bargaining. Then payoffs for the firm and for the worker in negotiations over wages, denoted respectively by $u_{f}\left(t_{f}, t_{w} ; \tau\right)$ and $u_{w}\left(t_{f}, t_{w} ; \tau\right)$, are as follows:

$$
\begin{gathered}
u_{f}\left(t_{f}, t_{w} ; \tau\right)=\left\{\begin{array}{ccc}
\pi_{w} e^{-r_{f} t_{f}} & \text { if } & \tau \leq t_{f}<t_{w} \\
\frac{\pi_{w}+\pi_{f}}{2} e^{-r_{f} t} & \text { if } & \tau \leq t_{f}=t_{w}=t \\
\pi_{f} e^{-r_{f} t_{w}} & \text { if } & \tau \leq t_{w}<t_{f} \\
\pi_{w} e^{-r_{f} \tau} & \text { if } & t_{f} \leq \min \left\{\tau, t_{w}\right\} \\
\frac{\pi_{w}+\pi_{f}}{2} e^{-r_{f} \tau} & \text { if } & t_{f}=t_{w}=t \leq \tau \\
\pi_{f} e^{-r_{f} \tau} & \text { if } \quad t_{w} \leq \min \left\{\tau, t_{f}\right\}
\end{array}\right. \\
u_{w}\left(t_{f}, t_{w} ; \tau\right)=\left\{\begin{array}{ccc}
w_{w} e^{-r_{w} t_{f}} & \text { if } \quad \tau \leq t_{f}<t_{w} \\
\frac{w_{w}+w_{f}}{2} e^{-r_{w} t} & \text { if } & \tau \leq t_{f}=t_{w}=t \\
w_{f} e^{-r_{w} t_{w}} & \text { if } \quad \tau \leq t_{w}<t_{f} \\
w_{w} e^{-r_{w} \tau} & \text { if } \quad t_{f} \leq \min \left\{\tau, t_{w}\right\} \\
\frac{w_{w}+w_{f}}{2} e^{-r_{w} \tau} & \text { if } \quad t_{f}=t_{w}=t \leq \tau \\
w_{f} e^{-r_{w} \tau} & \text { if } \quad t_{w} \leq \min \left\{\tau, t_{f}\right\}
\end{array}\right.
\end{gathered}
$$

For both payoff functions, the first three rows refer to payoffs when agreement over wages in this set of negotiations is reached after the time $\tau$ of agreement in firm-government 
negotiations. The three bottom rows refer instead to payoffs when agreement over wages is reached not later than the agreement in firm-government negotiations.

Negotiations between the firm and the government develop in similar fashion. Given the size of the total public stake $S$, let $h_{g}$ be the handout to the firm favoured by the government, and $h_{f}>h_{g}$ the outcome preferred by the firm. If agent $i=g, f$ concedes at time $\tau_{i}$, this means that an agreement is struck on government payment $h_{j \neq i}$. If both agents concede at the same time, then each of the two agreements is implemented with probability of $\frac{1}{2}$. As above, if there is already agreement in the firm-worker negotiations, then the settlement over the government's payout to the firm is implemented immediately. Alternatively, it is implemented as soon as an agreement is reached over wages. Let $t=\min \left\{t_{w}, t_{f}\right\}$ denote the time at which an agreement is reached in the parallel set of negotiations between the firm and the worker. Then payoffs for the firm (denoted by $\left.u_{f}\left(\tau_{f}, \tau_{g} ; t\right)\right)$ and the government (denoted by $\left.u_{g}\left(\tau_{f}, \tau_{g} ; t\right)\right)$ are

$$
\begin{aligned}
& u_{f}\left(\tau_{f}, \tau_{g} ; t\right)=\left\{\begin{array}{ccc}
h_{g} e^{-r_{f} \tau_{f}} & \text { if } \quad \tau \leq \tau_{f}<\tau_{g} \\
\frac{h_{g}+h_{f}}{2} e^{-r_{f} \tau} & \text { if } t \leq \tau_{f}=\tau_{g}=\tau \\
h_{f} e^{-r_{f} \tau_{g}} & \text { if } \quad t \leq \tau_{g}<\tau_{f} \\
h_{g} e^{-r_{f} t} & \text { if } \tau_{f} \leq \min \left\{t, \tau_{g}\right\} \\
\frac{h_{g}+h_{f}}{2} e^{-r_{f} t} & \text { if } \tau_{f}=\tau_{g}=\tau \leq t \\
h_{f} e^{-r_{f} t} & \text { if } \tau_{g} \leq \min \left\{t, \tau_{f}\right\}
\end{array}\right. \\
& u_{g}\left(\tau_{f}, \tau_{g} ; t\right)=\left\{\begin{array}{clc}
\left(S-h_{g}\right) e^{-r_{g} \tau_{f}} & \text { if } \quad t \leq \tau_{f}<\tau_{g} \\
\frac{\left(S-h_{g}\right)+\left(S-h_{f}\right)}{2} e^{-r_{g} \tau} & \text { if } t \leq \tau_{f}=\tau_{g}=\tau \\
\left(S-h_{f}\right) e^{-r_{g} \tau_{g}} & \text { if } \quad t \leq \tau_{g}<\tau_{f} \\
\left(S-h_{g}\right) e^{-r_{g} t} & \text { if } \quad \tau_{f} \leq \min \left\{t, \tau_{g}\right\} \\
\frac{\left(S-h_{g}\right)+\left(S-h_{f}\right)}{2} e^{-r_{g} t} & \text { if } \quad \tau_{f}=\tau_{g}=\tau \leq t \\
\left(S-h_{f}\right) e^{-r_{g} t} & \text { if } \quad \tau_{g} \leq \min \left\{t, \tau_{f}\right\}
\end{array}\right.
\end{aligned}
$$

In order to derive the equilibria it is convenient to start by looking at each war of attrition in isolation. Consider first the one between the firm-worker over wages. As 
a preliminary it is useful to define $t_{f}^{*}$ and $t_{w}^{*}$ as the times such that the firm and the worker, respectively, are indifferent between (i) holding on and obtaining its own proposal with delay, and (ii) conceding immediately to the opponent's proposal. Then $t_{f}^{*}$ solves $\pi_{f} e^{-r_{f} t}=\pi_{w}$ and $t_{w}^{*}$ solves $w_{w} e^{-r_{w} t}=w_{f}$, yielding

$$
t_{f}^{*}=\frac{1}{r_{f}} \ln \left(\frac{\pi_{f}}{\pi_{w}}\right)=\frac{1}{r_{f}} \ln \left(\frac{1-w_{f}}{1-w_{w}}\right)>0
$$

and

$$
t_{w}^{*}=\frac{1}{r_{w}} \ln \left(\frac{w_{w}}{w_{f}}\right)>0
$$

respectively. Note that the above imply that, at any time before these threshold times, the agent prefers to hold on rather than concede, since the payoff if conceding is less than the payoff if the opponent concedes at the threshold, that is

$$
\pi_{f} e^{-r_{f} t} \geq \pi_{w} \Leftrightarrow t \leq t_{f}^{*} \text { and } w_{w} e^{-r_{w} t} \geq w_{f} \Leftrightarrow t \leq t_{w}^{*}
$$

These threshold times are useful for the derivation of best response correspondences, to which I now turn. Suppose first that $\tau=0$ (so that there is immediate agreement in firm-government negotiations). The setup then collapses to the standard two players war of attrition in complete information ${ }^{8}$. As long as the worker concedes at some $t_{w}<t_{f}^{*}$, from the discussion above it is clear that the best response for the firm is to concede after the worker, setting $t_{f}>t_{w}$. If instead the worker chooses $t_{w}>t_{f}^{*}$, then the firm's best response is to concede immediately (i.e. $t_{f}=0$ ). Consider now the case when $\tau>0$, so that there is delayed agreement in firm-government negotiations. As long as $t_{w} \leq t_{f}^{*}$ the analysis is the same as the standard case. However, when $t_{w}$ is greater than $t_{f}^{*}$, whether or not it is a best response for the firm to concede depends on how large $\tau$ is, which in turn determines when the agreement is going to be implemented. For instance, even if the firm were to concede immediately (so that $t_{f}=0$ ), it would still have to wait up to

\footnotetext{
${ }^{8}$ This admits two pure strategy Nash equilibria which are symmetric and in which one of the agents concedes immediately. Equilibria with delayed agreement can only be obtained in mixed strategies.
} 
time $\tau$ in order to obtain $\pi_{f}$. Thus, if parties haggle in the parallel set of negotiations for a sufficiently long time (as measured by $\tau$ ), there may be an incentive for the firm to 'overlast' the worker (i.e. set $t_{f}>t_{w}$ ), as by so doing it obtains the higher share of surplus $\pi_{f}$. This is the case as long as

$$
\pi_{f} e^{-r_{f} t_{w}}>\pi_{w} e^{-r_{f} \tau}
$$

which is equivalent ${ }^{9}$ to

$$
\tau>t_{w}-t_{f}^{*}
$$

On the other hand, if

$$
\pi_{f} e^{-r_{f} t_{w}}<\pi_{w} e^{-r_{f} \tau} \Leftrightarrow \tau<t_{w}-t_{f}^{*}
$$

then any $t_{f} \leq \tau$ is a best response for the firm. The firm's best response correspondence is thus

$$
B_{f}\left(t_{w} ; \tau\right)=\left\{\begin{array}{clc}
\left\{t_{f}: t_{f}>t_{w}\right\} & \text { if } & t_{w}<t_{f}^{*} \\
\left\{t_{f}=0\right\} \cup\left\{t_{f}>t_{w}\right\} & \text { if } & t_{w}=t_{f}^{*} \\
\left\{t_{f}=0\right\} & \text { if } & t_{w}>t_{f}^{*} \text { and } \tau=0 \\
\left\{t_{f}: t_{f}>t_{w}\right\} & \text { if } & t_{w} \in\left(t_{f}^{*}, t_{f}^{*}+\tau\right] \text { and } \tau>0 \\
\left\{t_{f}: t_{f} \leq \tau\right\} & \text { if } & t_{w}>t_{f}^{*}+\tau \text { and } \tau>0
\end{array}\right.
$$

One can proceed similarly for the worker to obtain:

$$
B_{w}\left(t_{f} ; \tau\right)=\left\{\begin{array}{clc}
\left\{t_{w}: t_{w}>t_{f}\right\} & \text { if } & t_{f}<t_{w}^{*} \\
\left\{t_{w}=0\right\} \cup\left\{t_{w}>t_{f}\right\} & \text { if } & t_{f}=t_{w}^{*} \\
\left\{t_{w}=0\right\} & \text { if } & t_{f}>t_{w}^{*} \text { and } \tau=0 \\
\left\{t_{w}: t_{w}>t_{f}\right\} & \text { if } & t_{f} \in\left(t_{w}^{*}, t_{w}^{*}+\tau\right] \text { and } \tau>0 \\
\left\{t_{w}: t_{w} \leq \tau\right\} & \text { if } & t_{f}>t_{w}^{*}+\tau \text { and } \tau>0
\end{array}\right.
$$

\footnotetext{
${ }^{9}$ The above expression can be rearranged as $\frac{\pi_{f}}{\pi_{w}}>e^{r_{f}\left(t_{w}-\tau\right)}$. Taking logs on both sides and rearranging yields $\left(t_{w}-\tau\right)<\frac{1}{r_{f}} \ln \left(\frac{\pi_{f}}{\pi_{w}}\right)=t_{f}^{*}$, from which the expression in the text follows.
} 
Putting the two best response correspondences together one can identify the candidate equilibrium strategies for any given $\tau$, and verify that as long as $\tau$ is strictly positive it would be possible to support equilibria with delays in pure strategies. Figure 1 clarifies this point. The light grey areas denotes the firm's best response to any choice of stopping time for the worker, while the dark grey area identifies the worker's best response. Equilibrium outcomes correspond to the overlap of the two best response correspondences (checkered area in Figure 1). For instance, one such equilibrium outcome is with $\left(t_{f}=t_{w}^{*}+\tau, t_{w}=\tau\right)$, which correspond to the upper leftmost corner of the bottom overlap area in Figure 1.

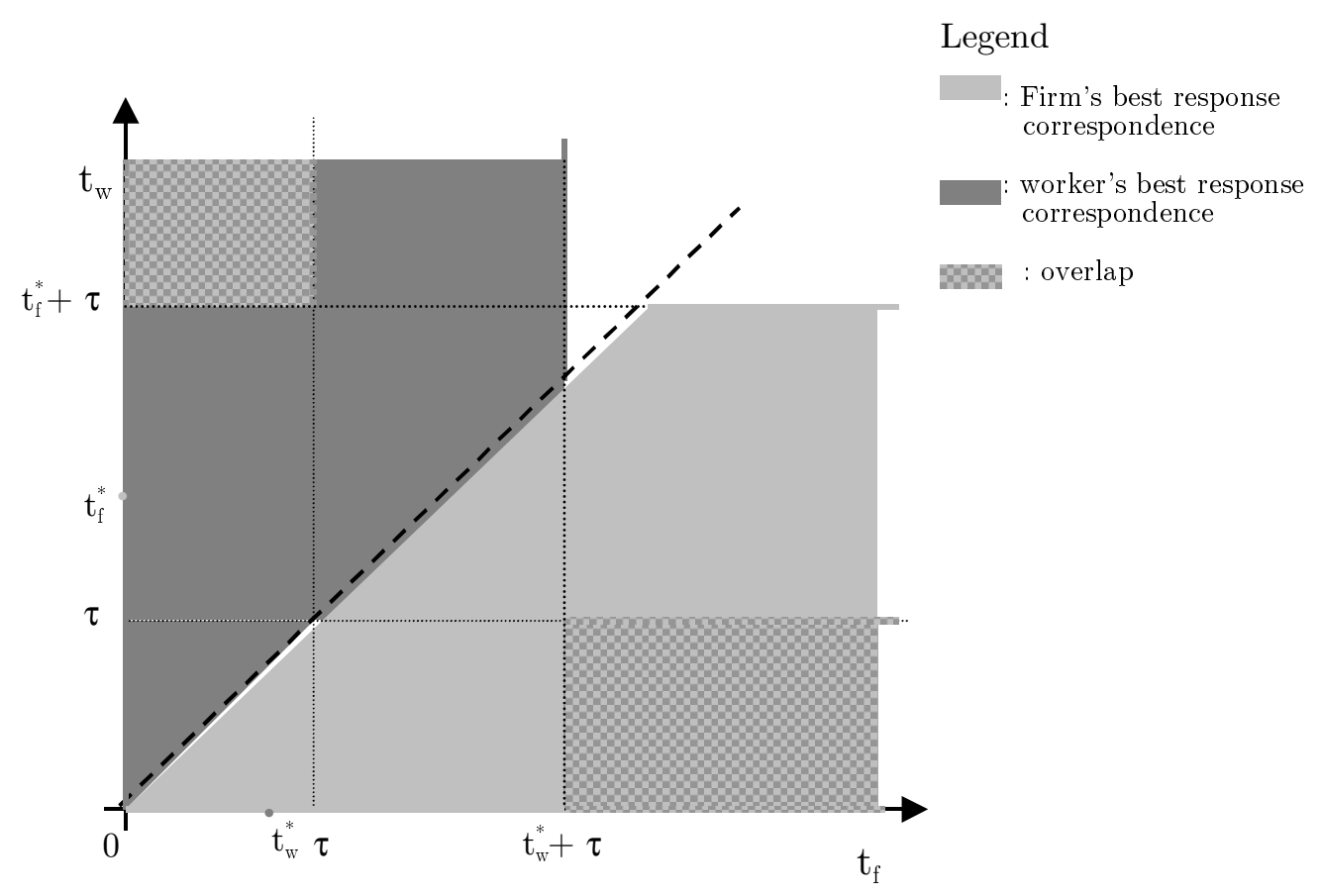

Figure 1: Best response correspondences for the worker and the firm in the war of attrition over wages.

More in general, the areas of overlap in Figure 1 identify the continuum of delayed equilibria. In these equilibria player $j$ concedes at time $t_{j} \leq \tau$ given that his opponent chooses $t_{i}>t_{j}^{*}+\tau$, whereby it is optimal for player $j$ to do since, by inspection of 
the best response correspondences above, $t_{i}>t_{i}-t_{j}^{*}>\tau \geq t_{j}$ is a best response to $t_{j}<\min \left\{t_{i}^{*}, \tau\right\}$. Thus one class is with the firm not conceding, i.e. $\left(t_{w}=x, t_{f}=t_{w}^{*}+x\right)$ where $x \leq \tau$ (bottom right overlap area). Similarly, one can construct a continuum of equilibria in which it is the worker who holds out for longer, i.e. $\left(t_{f}=y, t_{w}=t_{f}^{*}+y\right)$ with $y \leq \tau$ (top left overlap area).

The analysis of the firm-government war of attrition can be easily developed by following a similar line of argument. Define now $\tau_{f}^{*}$ and $\tau_{w}^{*}$ as the times such that the firm and the government, respectively, are indifferent between holding on - thereby obtaining their own proposal with delay - and conceding immediately to the opponent's proposal. These two values solve

$$
h_{g}=h_{f} e^{-r_{f} \tau} \Leftrightarrow \tau_{f}^{*}=\frac{1}{r_{f}} \ln \left(\frac{h_{f}}{h_{g}}\right)>0
$$

and

$$
\left(S-h_{f}\right)=\left(S-h_{g}\right) e^{-r_{g} \tau} \Leftrightarrow \tau_{g}^{*}=\frac{1}{r_{g}} \ln \left(\frac{S-h_{g}}{S-h_{f}}\right)>0
$$

respectively.

Then, by arguments similar to those followed for the war of attrition over wages, the best response correspondences for the firm and the government when negotiating over financial handout are:

$$
B_{f}\left(\tau_{g} ; t\right)=\left\{\begin{array}{clc}
\left\{\tau_{f}: \tau_{f}>\tau_{g}\right\} & \text { if } & \tau_{g}<\tau_{f}^{*} \\
\left\{\tau_{f}=0\right\} \cup\left\{\tau_{f}>\tau_{g}\right\} & \text { if } & \tau_{g}=\tau_{f}^{*} \\
\left\{\tau_{f}=0\right\} & \text { if } & \tau_{g}>\tau_{f}^{*} \text { and } t=0 \\
\left\{\tau_{f}: \tau_{f}>\tau_{g}\right\} & \text { if } & \tau_{g} \in\left(0, \tau_{f}^{*}+t\right] \text { and } t>0 \\
\left\{\tau_{f}: \tau_{f} \leq t\right\} & \text { if } & \tau_{g}>\tau_{f}^{*}+t \text { and } t>0
\end{array}\right.
$$

for the firm and: 


$$
B_{g}\left(\tau_{f} ; t\right)=\left\{\begin{array}{ccc}
\left\{\tau_{g}: \tau_{g}>\tau_{f}\right\} & \text { if } & t=0 \text { and } \tau_{f}<\tau_{w}^{*} \\
\left\{\tau_{g}=0\right\} \cup\left\{\tau_{g}>\tau_{f}\right\} & \text { if } & t=0 \text { and } \tau_{f}=\tau_{w}^{*} \\
\left\{\tau_{g}=0\right\} & \text { if } & t=0 \text { and } \tau_{f}>\tau_{w}^{*} \\
\left\{\tau_{g}: \tau_{g}>\tau_{f}\right\} & \text { if } & \tau_{f} \in\left(0, \tau_{w}^{*}+t\right] \text { and } t>0 \\
\left\{\tau_{g}: \tau_{g} \leq t\right\} & \text { if } & \tau_{f}>\tau_{w}^{*}+t \text { and } t>0
\end{array}\right.
$$

for the government. Here again if $t$ is strictly positive but not too large, there are equilibria with delays in pure strategies.

\section{Delayed equilibria}

It is now straightforward to put the two set of negotiations together and derive the equilibria of the game. Note that as the firm is engaged in both sets of negotiations, its strategies are obtained as the Cartesian product of the strategies available in each war of attrition.

It is immediate to verify that, as in the standard war of attrition, here as well there are equilibria with immediate agreement. In all these equilibria one agent backs down immediately, giving in to the (credible) threat that his opponent will hold on for long enough (i.e. beyond the threshold $t_{i}^{*}$ of the conceding agent $i$ ). It is however more interesting to consider whether in this simple setup delayed equilibria can arise in pure strategies. This can occur only if both set of negotiations are delayed: if either of the war of attritions were to end with immediate agreement, the best response correspondences in the parallel set of negotiations would reduce to a standard war of attrition, with immediate agreement in pure strategies. Thus all of $t_{f}, t_{w}, \tau_{f}$ and $\tau_{g}$ have to be positive. Once both wars of attrition are considered simultaneously, inspection of the best response correspondences yields immediately the following:

Lemma 1 Let $t_{i}, t_{j}, \tau_{p}, \tau_{q}$ (with $i, j=f, w$ and $p, q=f, g$ ) be such that for some $i$, 
$j, p$ and $q, t_{i} \leq \tau, t_{j}>t_{i}^{*}+\tau, \tau_{p} \leq t, \tau_{q}>\tau_{p}^{*}+t$, with $i \neq j, p \neq q$. Then a delayed agreement equilibrium exists.

The other interesting feature is in the lemma below, which establishes that in any delayed equilibrium both negotiations must end at the same time:

Lemma 2 Suppose the conditions for lemma 1 hold. In any delayed equilibrium it must be $\tau=t$.

Proof. Observe that the inequalities in lemma 1 imply that $t_{j}>t_{i}$ (since $t_{j}>$ $t_{i}^{*}+\tau \geq t_{i}^{*}+t_{i}>t_{i}$, where the central inequality uses $t_{i} \leq \tau$ ) and $\tau_{q}>\tau_{p}$ (since $\tau_{q}>\tau_{p}^{*}+t \geq \tau_{p}^{*}+\tau_{p}>\tau_{p}$, where the central inequality uses $\left.\tau_{p} \leq t\right)$. Consequently, $t=t_{i}$ and $\tau=\tau_{p}$. Then $t_{i} \leq \tau=\tau_{p}$ and $\tau_{p} \leq t=t_{i}$ can both hold only if $t=t_{i}=\tau_{p}=\tau$.

Lemma 2 underlines the crucial characteristic of the set of delayed equilibria: in all these equilibria, agents haggle for some time before agreeing. The intuition for this is very simple: as long as agent $j$ in one set of negotiations expects haggling in the parallel war of attrition, there is no point for this agent $j$ in giving in before the other negotiations are up. Thus, both sets of negotiators coordinate on terminating with some delay.

Figure 2 depicts one possible delayed Nash equilibrium outcome of the game. In the case illustrated the worker is the first to concede over wages, at time $x$, whereas the firm is the first to concede in negotiations over public money, also at time $x$.

The critical characteristic of delayed equilibria is that the firm uses strategically the fact that it participates in both negotiations, and that in by so doing it can singlehandedly impose delays to both the other negotiations. As long as this threat is credible, the other side of the negotiations will concede. Consequently, the firm never concedes in both negotiations. This is stated more formally in the following proposition, which establishes that in equilibrium either the firm holds on at least in the negotiations with the government (case 1 , where $\tau_{f}>\tau_{g}$ ) or it holds on at least in the negotiations with the worker (case 2, where $\left.t_{f}>t_{w}\right)$ : 

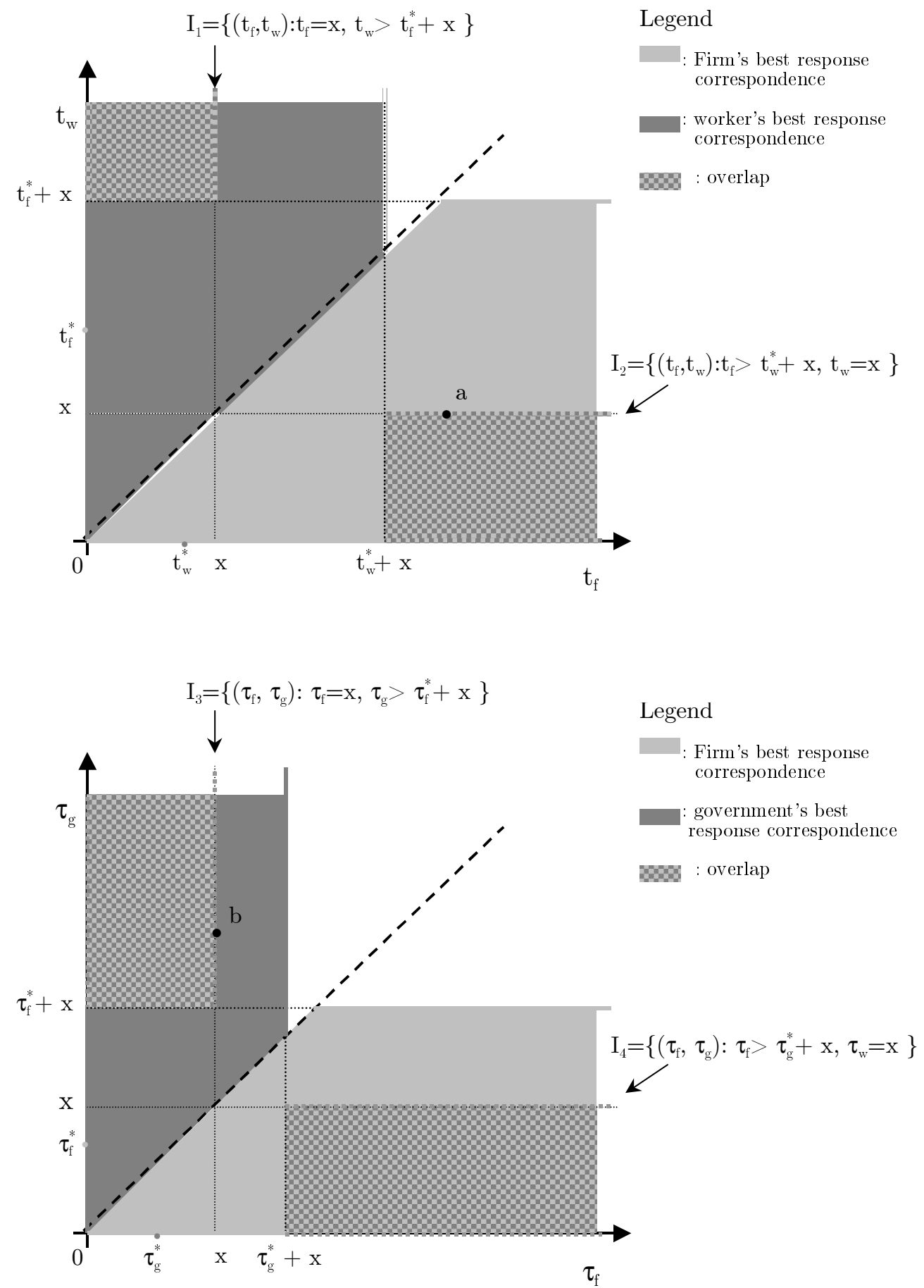

Figure 2: Points $\mathbf{a}$ and $\mathbf{b}$ denote one possible Nash equilibrium outcome, where $\tau_{f}=x=$ $t_{w}, \tau_{g}>\tau_{f}^{*}+x, t_{f}>t_{w}^{*}+x$. 
Proposition 3 Suppose the conditions of lemma 1 hold. For any $w_{i}, h_{j} \geq 0$ (with $i=w, f$ and $j=g, f)$ such that $w_{w}>w_{f}$ and $h_{g}<h_{f}$ let $\bar{x}_{w}=\frac{1}{r_{f}} \ln \left(\frac{1-w_{w}+h_{f}}{1-w_{w}+h_{g}}\right)$ and $\bar{x}_{g}=\frac{1}{r_{f}} \ln \left(\frac{1-w_{f}+h_{g}}{1-w_{w}+h_{g}}\right)$. Then the following fully characterises the pure strategy delayed equilibria of the game:

1. for any $x \in\left(0, \bar{x}_{w}\right)$ and $y, z \geq x$ the following is a delayed equilibrium:

$$
\left(t_{i}=x, t_{j}=t_{i}^{*}+y, \tau_{g}=x, \tau_{f}=\tau_{g}^{*}+z\right)
$$

2. for any $x \in\left(0, \bar{x}_{g}\right)$ and $y \geq x$ the following is a delayed equilibrium:

$$
\left(t_{w}=x, t_{f}=t_{w}^{*}+y, \tau_{p}=x, \tau_{q}=\tau_{p}^{*}+z\right)
$$

Proof. See Appendix.

The feature which emerges from the analysis of the equilibria is that the government and the workers are at a disadvantage in negotiations with the firm, which always prevails in at least one of the two negotiations. The intuition behind this result is that no unilateral deviation by either the government or the worker can impact on the overall outcome of negotiations. In fact, an earlier concession than as specified by the strategies in proposition 3 would not anticipate the overall end of negotiations. On the other hand, a deviation to holding on even further would not be profitable: although this may mean obtaining the most preferred settlement, this would come at a time which is late enough to make this proposition unappealing. To the contrary, unilateral deviations by the firm can indeed change the implementation date for all agreements, and it is this which gives the firm a stronger bargaining position.

Consequently, as established in Proposition 3, delayed equilibria can be only of three 'types': either the firm holds on in negotiations over wages, or in negotiations over public money, or in both. The firm never concedes in both at an equilibrium. This can be illustrated with the aid of figure 2 , where points $\mathbf{a}$ and $\mathbf{b}$ denote equilibrium stopping times in negotiations over wages and over government's handout, respectively. Then, 
Proposition 3 implies that in a delayed equilibrium either $\mathbf{a} \in I_{2}$ and $\mathbf{b} \in I_{3}$, i.e. the firm holds on in negotiations over wages, but gives in negotiations over public money, as in the example in the figure; or $\mathbf{a} \in I_{1}$ and $\mathbf{b} \in I_{4}$, or $\mathbf{a} \in I_{2}$ and $\mathbf{b} \in I_{4}$.

\section{Incompatible demands?}

So far I have assumed that negotiators start at the outset with incompatible demands, each of them favouring a different outcome. Although this is not an unreasonable assumption, it is worth investigating whether these demands can be endogenised in some "pre-war of attrition' stage, and what the impact is on the behaviour in the war of attrition. In this section the initial demands are endogenised: in the modified model the war of attrition stage is preceded by a bargaining phase in which agents choose their demands.

Each of the two negotiations (the one over wages and the one over the government handout) is thus composed of two phases. In the bargaining phase each of the two sides in the negotiations tables its proposal. If demands are compatible, then an agreement is reached. Alternatively, negotiations enter the war of attrition phase (as described in section 2). As in the base model, agents obtain their payoff only when both sets of negotiations are over. The bargaining phase is structured as a simple Nash demand game, where both sides involved table their claims/offers independently. Proposed wage settlements $w$ and government contributions $h$ are allowed to vary within some bounded interval, i.e. $w \in[\underline{w}, \bar{w}]$ and $h \in[\underline{h}, \bar{h}]$, with $\underline{w} \leq \bar{w}$ and $\underline{h} \leq \bar{h}$. For instance, there may be budgetary constraints on how much the stakeholder can contribute to support the firm, or there may be a minimum wage in operation.

In wage negotiations, $w_{f}$ and $w_{w}$ now denote the wage settlements put forward by the firm and the worker, respectively. If $w_{f} \geq w_{w}$, then these wages are compatible, and this set of negotiations ends in agreement, with the worker accepting $w_{f}$, leaving $\pi_{f}=1-w_{f}$ for the firm. If instead $w_{f}<w_{w}$, then negotiations enter the war of attrition stage described in section 2 . 
Negotiations between the firm and the government develop in similar fashion. Given the size of the total public stake $S$, let $h_{g}$ be the handout to the firm proposed by the government, and $h_{f}$ the claim by the firm. If $h_{g} \geq h_{f}$, negotiations end with the firm obtaining $h_{g}$ leaving a residual $S-h_{g}$ for the government. If instead $h_{g}<h_{f}$, negotiations enter the war of attrition stage.

In this setup, the bargaining phase is in effect the first stage of a negotiation game, with the war of attrition as second and final stage. Thus, in order to derive the equilibria of the two stage game we have to 'fold' the equilibrium behaviour in the war of attrition back one step to determine the optimal behaviour in the first stage (bargaining).

Obviously there are equilibria in which initial demands are compatible, so that agreement is reached immediately. In this equilibria any quadruple of compatible demands can be supported by the immediate equilibria of the second (war of attrition) stage. A more interesting question is to see whether the inefficient (delayed) equilibria of the base model are wiped out by the first stage, in which demands are chosen strategically. As I show below, the strategic incentives to delay agreement are still paramount, and delayed equilibria still occur in pure strategies:

Proposition 4 For any $w \in(0,1), h \in(0, S)$ let $\bar{y}_{g}=\frac{1}{r_{f}} \ln \frac{1-\underline{w}+\underline{h}}{1-\underline{w}+\underline{\underline{h}}}, \bar{y}_{w}=\frac{1}{r_{f}} \ln \frac{1-\bar{w}+\bar{h}}{1-\bar{w}+h}$, $\bar{y}_{0}=\frac{1}{r_{f}} \ln \frac{1-\underline{w}+\bar{h}}{1-w+h}$. Then:

1. Concession over Wage $(\mathbf{C W}):$ For any $x \in\left(0, \bar{y}_{w}\right)$ and $y, z \geq x$ there exists a subgame perfect equilibrium with delayed agreement in which the firm concedes in bargaining over wages. In this equilibrium the worker obtains the highest wage $\bar{w}$. Supporting strategies are as follows:

$$
\left(w_{w}=\bar{w}, t_{w}=t_{f}^{*}+y\right),\left(w_{f}=w, h_{f}=\bar{h}, t_{f}=x, \tau_{f}=\tau_{g}^{*}+z\right),\left(h_{g}=h, \tau_{g}=x\right)
$$

2. Concession over Handout $(\mathbf{C H})$ : For any $x \in\left(0, \bar{y}_{g}\right)$ and $y, z \geq x$ there exists is a subgame perfect equilibrium with delayed agreement in which the firm concedes in 
bargaining over the government handout. In this equilibrium the firm obtains the minimum handout $\underline{\text { }}$. Supporting strategies are as follows:

$$
\left(w_{w}=w, t_{w}=x\right),\left(w_{f}=\underline{w}, h_{f}=h, t_{f}=t_{w}^{*}+y, \tau_{f}=x\right),\left(h_{g}=\underline{h}, \tau_{g}=\tau_{g}^{*}+z\right)
$$

3. No Concessions (NC): For any $x \in\left(0, \bar{y}_{0}\right)$ and $y, z \geq x$ there exists is a subgame perfect equilibrium with delayed agreement in which the firm holds out in both sets of negotiations. Supporting strategies are as follows:

$$
\left(w_{w}=w, t_{w}=x\right),\left(w_{f}=\underline{w}, h_{f}=\bar{h}, t_{f}=t_{w}^{*}+y, \tau_{f}=\tau_{g}^{*}+z\right),\left(h_{g}=h, \tau_{g}=x\right)
$$

Proof. See Appendix.

The proposition above establishes that delays can still occur even when agents can formulate their initial demands: it pays to risk delay by setting as high a claim as possible if the claim is eventually successful. To see this, recall from the discussion of proposition 3 that in both sets of negotiations the worker and the government are somewhat at a disadvantage, in that any unilateral deviation is not sufficient to anticipate agreement. A deviation may be sufficient to postpone agreement, but this is never profitable. To the contrary, because it is involved in both sets of negotiations, the firm is the only player that could single-handedly impose an immediate agreement. This, however, would mean accepting the opponents' proposals, and as long as the demand put forward is sufficiently attractive, the firm has an incentive to haggle. The crucial feature of the delayed equilibria of the game is that in each set of negotiations both agents start out with incompatible demands, but one of them will prevail. Consequently, it is optimal for such 'strong' negotiator to set his initial demand as high as possible.

\section{Discussion}

The upshot of this paper is that whenever negotiations can be configured as running in parallel with interconnected surplus and one player in common, inefficiencies are rife: 
although the model does allow for efficient equilibria - where agreement is immediate - delayed equilibria are a pervasive phenomenon. One prediction of the model is thus that industrial relations in sectors of public interest should be characterised by a higher degree of conflict: as discussed in the introduction, in this case the possibility of strikes has an impact on the public at large, so that the government has a stake in the firmworkforce negotiations. Consequently, one should really look at the 'meta-negotiations' which involve the firm and its workforce on one side, and the government and one of the other agents on the other, depending on the exact nature of the dispute. Indeed, there is evidence in support of this. For instance, in Canada the share of total strike days lost in the public sector relative to the private sector has increased ${ }^{10}$ since the mid 1970s.

As discussed above, the rationale for this result is the fact that two sets of negotiations are interdependent implies that an agreement can be implemented only once all issues have been settled; this may introduce an incentive for the pivotal agent (i.e. that involved in both negotiations) to delay agreement in order to win the maximum concessions from one's opponents. This feature also makes it possible for inefficiencies to persist even once the initial demands are endogenised: although there exist equilibria with immediate agreement, once more the linkage between the two sets of negotiations creates an incentive for delay. Interestingly, this would not be possible if the first stage of negotiations was followed by a standard war of attrition game, where delays are generally obtained only under incomplete information ${ }^{11}$.

Thus it would appear that it is the existence of a wider interest which generates the possibility for one party to take a pivotal role and act strategically to its maximum advantage.

\footnotetext{
${ }^{10}$ See $[3]$.

${ }^{11}$ See [1] and [6], who study the equilibria of bargaining games under incomplete information when players can be "stubborn", i.e. insist on receiving a particular share.
} 


\section{Appendix}

\section{Proof of proposition 3}

Observe that in all cases $x=\min \left\{t_{w}, t_{f}\right\}=\min \left\{\tau_{f}, \tau_{g}\right\}$. Then no agent has a profitable deviation. Consider the worker first. In case 1 , if $i=f$, then it cannot be profitable for the worker to concede at any different time, since given the other agents' equilibrium strategies, his payoff would remain unchanged (note that if he conceded earlier than the firm - at a time $t_{w}<t_{f}=x$ - he would still have to wait until agreement is reached in the other set of negotiations at time $x$ ). Consider now the possibility that $i=w$, so that in both cases 1 and 2 it is the worker who concedes first (obtaining a share $w_{f}$ ). A deviation to hold on further can only be profitable if the worker can do so until the firm concedes (otherwise he would get still $w_{f}$, but later, since he would push forward the implementation of all agreements), so that he can obtain the higher wage $w_{w}$, although later. Suppose then that the worker deviates to $t_{w}^{\prime}=t_{w}^{*}+y+\varepsilon$, with $\varepsilon>0$ and arbitrarily small. Because the worker is now pushing the date of implementation of all agreements forward, his payoff from this deviation is $w_{w} e^{-r_{w} t_{w}^{\prime}}$, which is smaller than the equilibrium payoff $w_{f} e^{-r_{w} x}$ since

$$
w_{w} e^{-r_{w} t_{w}^{\prime}}<w_{f} e^{-r_{w} x} \Leftrightarrow \frac{w_{w}}{w_{f}}<e^{r_{w}\left(t_{w}^{\prime}-x\right)} \Leftrightarrow t_{w}^{\prime}>\frac{1}{r_{w}} \ln \left(\frac{w_{w}}{w_{f}}\right)+x=t_{w}^{*}+x
$$

where the last inequality is true by the definition of $t_{w}^{\prime}$ (recall that $y \geq x$ ). Similar reasoning shows that there can be no profitable deviation for the government. For the latter the only possibility to consider is when $p=g$ (in case 2 ) and the government deviate to hold on further than the firm, until time $\tau_{g}^{\prime}=\tau_{g}^{*}+z+\varepsilon$. In this case the deviation payoff would be $\left(S-h_{g}\right) e^{-r_{g} t_{g} \prime}$, which does not improve on the equilibrium payoff $\left(S-h_{f}\right) e^{-r_{g} x}$ since

$$
\left(S-h_{g}\right) e^{-r_{g} \tau_{g}^{\prime}}<\left(S-h_{f}\right) e^{-r_{g} x} \Leftrightarrow \frac{S-h_{g}}{S-h_{f}}<e^{r_{g}\left(\tau_{g}^{\prime}-x\right)} \Leftrightarrow \tau_{g}^{\prime}>\frac{1}{r_{g}} \ln \left(\frac{S-h_{g}}{S-h_{f}}\right)+x=\tau_{w}^{*}+x
$$


where as above the last inequality holds by the choice of $\tau_{g}^{\prime}$ (recall that $z \geq x$ ). Finally, consider the firm. In case 1 when $i=w$ and in case 2 when $p=g$ the only potentially profitable deviation is to concede before $x$ in both negotiations (which is the only way in which the firm's payoff can be positively affected - if the firm conceded in only one bargain, it would decrease its payoff in that negotiation without any impact on the implementation date). So, if the firm is to deviate, it will set $t_{f}=\tau_{f}=x-\varepsilon \geq 0$. The corresponding payoff is thus $\pi_{w}+h_{g}$, so that this deviation is not profitable since

$$
\left(\pi_{w}+h_{g}\right) e^{-r_{f}(x-\varepsilon)}<\left(\pi_{f}+h_{f}\right) e^{-r_{f} x} \Leftrightarrow \varepsilon<\frac{1}{r_{f}} \ln \left(\frac{\pi_{f}+h_{f}}{\pi_{w}+h_{g}}\right)
$$

where the last inequality holds true since

$$
\varepsilon \leq x<\bar{x}_{w}=\frac{1}{r_{f}} \ln \left(\frac{1-w_{w}+h_{f}}{1-w_{w}+h_{g}}\right)=\frac{1}{r_{f}} \ln \left(\frac{\pi_{w}+h_{f}}{\pi_{w}+h_{g}}\right)<\frac{1}{r_{f}} \ln \left(\frac{\pi_{f}+h_{f}}{\pi_{w}+h_{g}}\right)
$$

for case 1 and

$$
\varepsilon \leq x<\bar{x}_{g}=\frac{1}{r_{f}} \ln \left(\frac{1-w_{f}+h_{g}}{1-w_{w}+h_{g}}\right)=\frac{1}{r_{f}} \ln \left(\frac{\pi_{f}+h_{g}}{\pi_{w}+h_{g}}\right)<\frac{1}{r_{f}} \ln \left(\frac{\pi_{f}+h_{f}}{\pi_{w}+h_{g}}\right)
$$

for case 2. Suppose now $i=f$ in case 1 . A deviation to giving in later on in negotiations over wages, at time $t_{f}^{\prime}$ say, can only have an impact on payoffs if $t_{f}^{\prime}>t_{w}=t_{f}^{*}+y$. Then let $t_{f}^{\prime}=t_{f}^{*}+y+\varepsilon$, so that the firm's payoff from this deviation is $\left(\pi_{f}+h_{f}\right) e^{-r_{f}\left(t_{f}^{*}+y+\varepsilon\right)}$. For this deviation to be profitable it must be

$$
\left(\pi_{f}+h_{f}\right) e^{-r_{f}\left(t_{f}^{*}+y+\varepsilon\right)}>\left(\pi_{w}+h_{f}\right) e^{-r_{f} x} \Leftrightarrow \frac{1}{r_{f}} \ln \left(\frac{\pi_{f}+h_{f}}{\pi_{w}+h_{f}}\right)>t_{f}^{*}+(y-x)+\varepsilon>t_{f}^{*}
$$

This generates a contradiction, as

$$
t_{f}^{*}=\frac{1}{r_{f}} \ln \left(\frac{\pi_{f}}{\pi_{w}}\right)>\frac{1}{r_{f}} \ln \left(\frac{\pi_{f}+h_{f}}{\pi_{w}+h_{f}}\right) \Leftrightarrow \pi_{f}>\pi_{w}
$$

A deviation to some earlier time $t_{f}^{\prime}=x-\varepsilon \geq 0$ in both negotiations ${ }^{12}$ would also be non profitable, as the firms' payoff after this deviation would be $\left(\pi_{w}+h_{g}\right) e^{-r_{f}(x-\varepsilon)}$, which is

\footnotetext{
${ }^{12}$ Recall that if the firm were to give in earlier in negotiations over wages only, the overall time of agreement would be left unchanged, whereas its share in the war of attrition with the worker would be reduced to $\pi_{w}$.
} 
smaller than the equilibrium payoff $\left(\pi_{w}+h_{f}\right) e^{-r_{f} x}$ since

$$
\left(\pi_{w}+h_{g}\right) e^{-r_{f}(x-\varepsilon)}<\left(\pi_{w}+h_{f}\right) e^{-r_{f} x} \Leftrightarrow \varepsilon<\frac{1}{r_{f}} \ln \left(\frac{\pi_{w}+h_{f}}{\pi_{w}+h_{g}}\right)
$$

where the last inequality holds true since

$$
\varepsilon \leq x<\bar{x}_{w}=\frac{1}{r_{f}} \ln \left(\frac{1-w_{w}+h_{f}}{1-w_{w}+h_{g}}\right)=\frac{1}{r_{f}} \ln \left(\frac{\pi_{w}+h_{f}}{\pi_{w}+h_{g}}\right)
$$

Similar arguments can be used to show that there can be no profitable deviations in the symmetric situation where $p=f$ in case 2 . As above, in this case the only payoff relevant deviations are if either (i) the firm holds on in negotiations over public money until time $\tau_{f}^{\prime}=\tau_{f}^{*}+z+\varepsilon$, or (ii) if it concedes earlier in both negotiations, at time $\tau_{f}^{\prime}=x-\varepsilon \geq 0$. Consider (i) first. The payoff following a deviation becomes then $\left(\pi_{f}+h_{f}\right) e^{-r_{f}\left(\tau_{f}^{*}+z+\varepsilon\right)}$, which is however less than the equilibrium payoff $\left(\pi_{f}+h_{g}\right) e^{-r_{f} x}$ since the contrary would require

$$
\left(\pi_{f}+h_{f}\right) e^{-r_{f f}\left(\tau_{f}^{*}+z+\varepsilon\right)}>\left(\pi_{f}+h_{g}\right) e^{-r_{f} x} \Leftrightarrow \frac{1}{r_{f}} \ln \left(\frac{\pi_{f}+h_{f}}{\pi_{f}+h_{g}}\right)>\tau_{f}^{*}+(z-x)+\varepsilon>\tau_{f}^{*}
$$

which in turn generates a contradiction, as

$$
\tau_{f}^{*}=\frac{1}{r_{f}} \ln \left(\frac{h_{f}}{h_{g}}\right)>\frac{1}{r_{f}} \ln \left(\frac{\pi_{f}+h_{f}}{\pi_{f}+h_{g}}\right) \Leftrightarrow h_{f}>h_{g}
$$

Turning now to (ii), the firm's payoff after deviating and conceding earlier in both negotiations, at time $\tau_{f}^{\prime}=x-\varepsilon \geq 0$ would be $\left(\pi_{w}+h_{g}\right) e^{-r_{f}(x-\varepsilon)}$, which is smaller than the equilibrium payoff $\left(\pi_{f}+h_{g}\right) e^{-r_{f} x}$ since

$$
\left(\pi_{w}+h_{g}\right) e^{-r_{f}(x-\varepsilon)}<\left(\pi_{f}+h_{g}\right) e^{-r_{f} x} \Leftrightarrow \varepsilon<\frac{1}{r_{f}} \ln \left(\frac{\pi_{f}+h_{g}}{\pi_{w}+h_{g}}\right)
$$

where the last inequality holds true since

$$
\varepsilon \leq x<\bar{x}_{g}=\frac{1}{r_{f}} \ln \left(\frac{1-w_{f}+h_{g}}{1-w_{w}+h_{g}}\right)=\frac{1}{r_{f}} \ln \left(\frac{\pi_{f}+h_{g}}{\pi_{w}+h_{g}}\right)
$$

Finally note that cases 1 and 2 completely exhaust all delayed equilibria. The only combination of stopping times not covered by cases 1 and 2 is if in a delayed equilibrium the firm concedes first in both sets of negotiations. This cannot be part of an equilibrium, though, as the firm could profitably deviate by conceding in both negotiations at time $t_{f}^{\prime}=\tau_{f}^{\prime}=x-\varepsilon$, thereby obtaining the same shares earlier. 


\section{Proof of proposition 4}

By proposition 3 , if $x \in\left(0, \bar{x}_{w}\right)$, in the second stage of the game the delayed equilibrium with $\left(t_{f}=x=\tau_{g}, t_{j}=t_{i}^{*}+y, \tau_{f}=\tau_{g}^{*}+z\right)$ can be supported. Substitution of $w_{w}=\bar{w}, w_{f}=w, h_{f}=\bar{h}$ and $h_{g}=h$ into $\bar{x}_{w}$ yields $x \in\left(0, \frac{1}{r_{f}} \ln \frac{1-\bar{w}+\bar{h}}{1-\bar{w}+h}\right)$, so that strategies $\boldsymbol{C W}$ in case 1 above are in equilibrium in the war of attrition stage. Similarly, by proposition 3 in the second stage of the game the delayed equilibrium with $\left(t_{w}=x, t_{f}=t_{w}^{*}+y, \tau_{f}=x, \tau_{f}=\tau_{p}^{*}+z\right)$ can be supported if $x \in\left(0, \bar{x}_{g}\right)$. Substitution of $w_{w}=w, w_{f}=\underline{w}, h_{f}=h$ and $h_{g}=\underline{h}$ into $\bar{x}_{g}$ yields $x \in\left(0, \frac{1}{r_{f}} \ln \frac{1-\underline{w}+\underline{h}}{1-w+\underline{h}}\right)$, so that strategies $\boldsymbol{C H}$ in case 2 above are in equilibrium in the second stage. Next, by the proof of proposition 3 (see condition 1) in the second stage of the game the delayed equilibrium with $\left(t_{w}=x, t_{f}=t_{w}^{*}+y, \tau_{f}=\tau_{g}^{*}+z, \tau_{g}=x\right)$ can be supported if $x \in\left(0, \frac{1}{r_{f}} \ln \left(\frac{1-w_{f}+h_{f}}{1-w_{w}+h_{g}}\right)\right)$.

Substitution of $w_{w}=w, w_{f}=\underline{w}, h_{f}=\bar{h}$ and $h_{g}=h$ yields $x \in\left(0, \frac{1}{r_{f}} \ln \left(\frac{1-\underline{w}+\bar{h}}{1-w+h}\right)\right)$, so that strategies $\boldsymbol{N C}$ in case 3 are in equilibrium in the second stage. Consequently, we only have to check for deviations in the first stage. Consider the worker first. If he were to deviate and asked $1-w_{f}$, his payoff still would not be affected, as because of incompatible demands in the parallel set of negotiations the game would still enter the second stage, with termination at time $t=x$. Similarly for the government. Consider now the firm. For equilibrium $\boldsymbol{C W}$ in case 1, a deviation in the first stage to compatible payoffs would yield the firm

$$
1-w_{w}+h_{g}<\left(1-w_{w}+h_{f}\right) e^{-r_{f} x} \Leftrightarrow x<\frac{1}{r_{f}} \ln \frac{\left(1-w_{w}+h_{f}\right)}{1-w_{w}+h_{g}}
$$

which is simply

$$
1-\bar{w}+h<(1-\bar{w}+\bar{h}) e^{-r_{f} x} \Leftrightarrow x<\frac{1}{r_{f}} \ln \frac{1-\bar{w}+\bar{h}}{1-\bar{w}+h}
$$

where the last inequality holds true because of $x<\bar{y}_{w}=\frac{1}{r_{f}} \ln \frac{1-\bar{w}+\bar{h}}{1-\bar{w}+h}$.

Consider now the equilibrium $\boldsymbol{C H}$ of case 2 above. For the firm a deviation in the first stage to compatible payoffs would yield the firm

$1-w_{w}+h_{g}=1-w+\underline{h}<(1-\underline{w}+h) e^{-r_{f} x}=\left(1-w_{f}+h_{g}\right) e^{-r_{f} x} \Leftrightarrow x<\frac{1}{r_{f}} \ln \frac{1-\underline{w}+\underline{h}}{1-w+\underline{h}}$ 
where the last inequality holds true since $x<\bar{y}_{g}=\frac{1}{r_{f}} \ln \frac{1-\underline{w}+\underline{h}}{1-\underline{w}+\underline{h}}$. Finally consider equilibrium $\boldsymbol{N C}$. The firm's equilibrium continuation payoff in the second stage is $\left(1-w_{f}+h_{f}\right) e^{-r_{f} x}=$ $(1-\underline{w}+\bar{h}) e^{-r_{f} x}$. By deviating to compatible demands ${ }^{13}$ the firm would get $1-w_{w}+h_{g}=$ $1-w+h$ immediately. But

$$
1-w+h<(1-\underline{w}+\bar{h}) e^{-r_{f} x} \Leftrightarrow x<\frac{1}{r_{f}} \ln \frac{1-\underline{w}+\bar{h}}{1-w+h}
$$

which holds true since $x<\bar{y}_{0}=\frac{1}{r_{f}} \ln \frac{1-\underline{w}+\bar{h}}{1-w+h}$.

Finally, recall from proposition 3 that delayed equilibria in the war of attrition subgame can be supported only if $x$ satisfies the necessary conditions. Furthermore, in the bargaining phase for the player who anticipates that his proposal will prevail in the second stage it is suboptimal to set his claim/offer to a value which is different from either the highest (for the firm) or the lowest (for the worker and the government). Thus those characterised above are the only equilibrium configurations possible for delayed agreement in pure strategies.

\section{References}

[1] Abreu, D. and F. Gul "Bargaining and Reputation", Econometrica, vol. 68, pp. 85$117,2000$.

[2] Bulow, J. and P. Klemperer "The Generalised War of Attrition", American Economic Review, vol.89, pp. 175-189, 1999.

[3] Gunderson, Morley, Douglas Hyatt and Allen Ponak "Strikes and Dispute Resolution", in M. Gunderson, A. Ponak and D. Taras (eds.) Union-Management Relations in Canada, Don Mills: Pearson, pp. 314-358, 2001.

\footnotetext{
${ }^{13}$ This deviation must affect both demand games, as otherwise the war of attrition stage would be triggered, and the firm would still receive its payoff with delay, but out of a smaller share.
} 
[4] Hendricks, K., A. Weiss and C. Wilson, "The War of Attrition in Continuous Time with Complete Information", International Economic Review, vol. 29, pp. 663-680.

[5] Institute for Public Policy Research article, "A discussion on an active industrial policy - lessons of Longbridge", IPPR, London, Friday, September 22, 2000.

[6] Kambe, S. "Bargaining with Imperfect Commitment", Games and Economic Behavior, vol. 28, pp. 217-237, 1999.

[7] LaCasse, C., C. Ponsatí and V. Barham "Chores", forthcoming, Games and Economic Behavior, 2001.

[8] Manzini, P. and C. Ponsatí "Stakeholders, Bargaining and Strikes", IZA DP No. 395, IZA Bonn, November 2001.

[9] Muthoo, A. , Bargaining: Theory with Applications, Cambridge University Press, 1999.

[10] Osborne, M. and A. Rubinstein, Bargaining and Markets, MIT Press, Cambridge, Mass., 1990.

[11] Osborne, M. and A. Rubinstein, A Course in Game Theory, MIT Press, Cambridge, Mass., 1994.

[12] Ponsatí, C. "Economic Diplomacy", mimeo, Universitat Autónoma de Barcelona, 2001. 


\section{IZA Discussion Papers}

\begin{tabular}{|c|c|c|c|c|}
\hline No. & Author(s) & Title & Area & Date \\
\hline 406 & $\begin{array}{l}\text { P. Garibaldi } \\
\text { E. Wasmer }\end{array}$ & $\begin{array}{l}\text { Labor Market Flows and Equilibrium Search } \\
\text { Unemployment }\end{array}$ & 1 & $11 / 01$ \\
\hline 407 & $\begin{array}{l}\text { R. Schettkat } \\
\text { L. Yocarini }\end{array}$ & $\begin{array}{l}\text { Education Driving the Rise in Dutch Female } \\
\text { Employment: Explanations for the Increase in } \\
\text { Part-time Work and Female Employment in the } \\
\text { Netherlands; Contrasted with Germany }\end{array}$ & 5 & $12 / 01$ \\
\hline 408 & $\begin{array}{l}\text { H. N. Mocan } \\
\text { E. Tekin }\end{array}$ & $\begin{array}{l}\text { Nonprofit Sector and Part-Time Work: An } \\
\text { Analysis of Employer-Employee Matched Data } \\
\text { of Child Care Workers }\end{array}$ & 1 & $12 / 01$ \\
\hline 409 & $\begin{array}{l}\text { P. Apps } \\
\text { R. Rees }\end{array}$ & Fertility, Female Labor Supply and Public Policy & 6 & $12 / 01$ \\
\hline 410 & $\begin{array}{l}\text { H. Lehmann } \\
\text { J. Wadsworth }\end{array}$ & $\begin{array}{l}\text { Wage Arrears and the Distribution of Earnings in } \\
\text { Russia }\end{array}$ & 4 & $12 / 01$ \\
\hline 411 & S. Stillman & $\begin{array}{l}\text { The Response of Consumption in Russian } \\
\text { Households to Economic Shocks }\end{array}$ & 4 & $12 / 01$ \\
\hline 412 & $\begin{array}{l}\text { M. Barbie } \\
\text { M. Hagedorn } \\
\text { A. Kaul }\end{array}$ & $\begin{array}{l}\text { Government Debt as Insurance against } \\
\text { Macroeconomic Risk }\end{array}$ & 7 & $12 / 01$ \\
\hline 413 & $\begin{array}{l}\text { H. Bonin } \\
\text { R. Euwals }\end{array}$ & $\begin{array}{l}\text { Participation Behavior of East German Women } \\
\text { after German Unification }\end{array}$ & 1 & $12 / 01$ \\
\hline 414 & $\begin{array}{l}\text { A. Frederiksen } \\
\text { N. Westergaard- } \\
\text { Nielsen }\end{array}$ & Where Did They Go? & 1 & $01 / 02$ \\
\hline 415 & $\begin{array}{l}\text { M. Bertrand } \\
\text { F. Kramarz }\end{array}$ & $\begin{array}{l}\text { Does Entry Regulation Hinder Job Creation? } \\
\text { Evidence from the French Retail Industry }\end{array}$ & 6 & $01 / 02$ \\
\hline 416 & $\begin{array}{l}\text { B. Crépon } \\
\text { F. Kramarz }\end{array}$ & $\begin{array}{l}\text { Employed } 40 \text { Hours or Not-Employed 39: } \\
\text { Lessons from the } 1982 \text { Mandatory Reduction of } \\
\text { the Workweek }\end{array}$ & 6 & $01 / 02$ \\
\hline 417 & J. Wagner & $\begin{array}{l}\text { Taking a Second Chance: } \\
\text { Entrepreneurial Restarters in Germany }\end{array}$ & 1 & $01 / 02$ \\
\hline 418 & $\begin{array}{l}\text { M. Frölich } \\
\text { P. A. Puhani }\end{array}$ & $\begin{array}{l}\text { Immigration and Heterogeneous Labor in } \\
\text { Western Germany: A Labor Market } \\
\text { Classification Based on Nonparametric } \\
\text { Estimation }\end{array}$ & 2 & $01 / 02$ \\
\hline 419 & $\begin{array}{l}\text { P. Frijters } \\
\text { J. P. Haisken-DeNew } \\
\text { M. A. Shields }\end{array}$ & $\begin{array}{l}\text { The Value of Reunification in Germany: } \\
\text { An Analysis of Changes in Life Satisfaction }\end{array}$ & 6 & $01 / 02$ \\
\hline 420 & $\begin{array}{l}\text { A. Rosén } \\
\text { E. Wasmer }\end{array}$ & $\begin{array}{l}\text { Higher Education Levels, Firms' Outside Options } \\
\text { and the Wage Structure }\end{array}$ & 1 & $01 / 02$ \\
\hline 421 & P. Manzini & Divide et Impera: Negotiating with a Stakeholder & 6 & $02 / 02$ \\
\hline
\end{tabular}

